\title{
Antenna Engineering for Various Applications with Low-Cost Product Manufacturing
}

SURESH CHINNATHAMPY M ( $\square$ sureshchinnathampy@gmail.com )

Francis Xavier Engineering College https://orcid.org/0000-0003-4172-8017

Ancy Marzla

Francis Xavier Engineering College

\section{Short Report}

Keywords:

Posted Date: February 23rd, 2022

DOI: https://doi.org/10.21203/rs.3.rs-1056985/v1

License: (c) (i) This work is licensed under a Creative Commons Attribution 4.0 International License. Read Full License 


\title{
Antenna Engineering for Various Applications with Low-Cost Product Manufacturing
}

\author{
M. Suresh Chinnathampy ${ }^{1}$ \\ A. Ancy Marzla ${ }^{2}$ \\ 1,2 Francis Xavier Engineering College (An Autonomous Institution), Tirunelveli - 627003, \\ Tamilnadu, INDIA. \\ e-mail: mailto:sureshchinnathampy@gmail.com ${ }^{1}$, mailto:ancymarzla@gmail.com ${ }^{2}$
}

\begin{abstract}
In this short communication, it is premeditated to specify various types of antennas used in different field with low-cost product manufacturing. Antenna means for radiating radio waves, Generally the type of antenna that are used in cell phone handsets in the form of Sleeve dipoles, Whip antennas. In Figure [1] the sleeve dipoles we have a coaxial transmission line, dielectric insert, metal sleeve and line braid. The balancing mode can be achievable with metal sleeve also the stability of the radiation pattern. The role of the dielectric and sleeve are not only maintaining the radiation pattern stable but also walk on the matching. Whenever we have the roll over mobile it is used for getting signal as well as receive signal. Capturing of signal is possible when the mobile starts working. The system represents the capturing of omni directional signal through radiation pattern measurements.
\end{abstract}

\section{Introduction}

The coaxial line inner conductor is along the $\mathrm{Z}$ - direction, the signal is symmetric along $\mathrm{X}-\mathrm{Y}$ plane. The construction of the whip antenna must be compact.

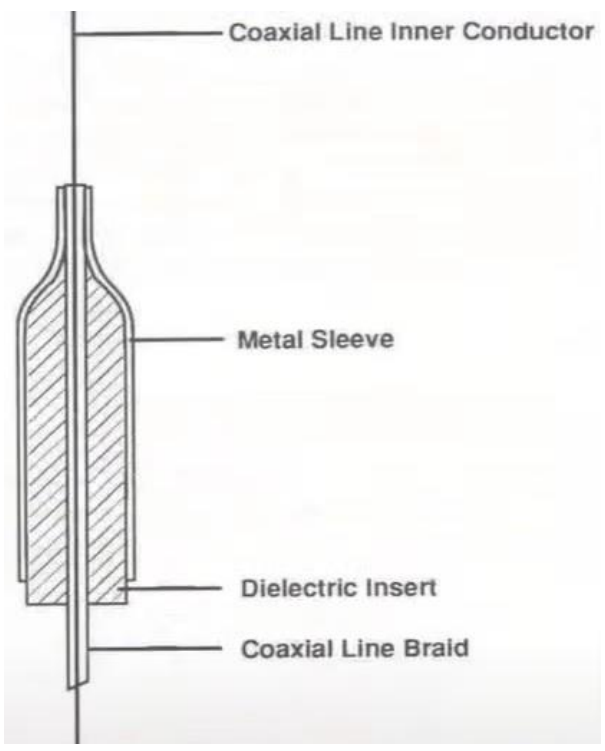

Figure 1: Handset Sleeve Dipole 
A spring in the whip antenna plays a vital role as small compact antenna systems which is usually implemented for cell phones. The small compact antenna used for transmitting and receiving signals in an omni-directional system.

The printed technology played a very significant role. From the cell phone perspective technology, the printed technology made a significant role which helps in use meandered monopoles used in MEMS.

\section{a. Meandered Monopole and Inverted F - Antenna (IFAs)}

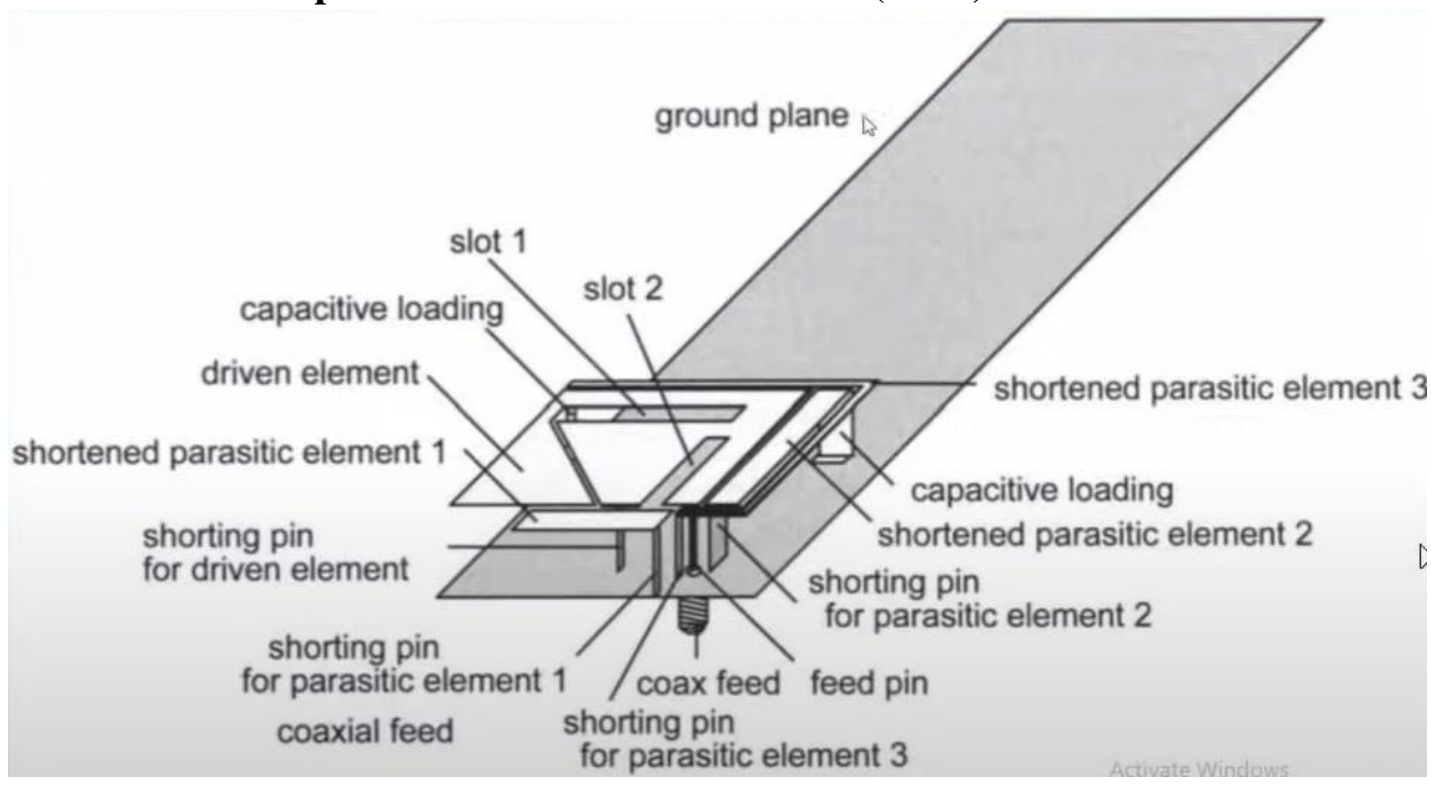

Figure 2: Meandered Monopole

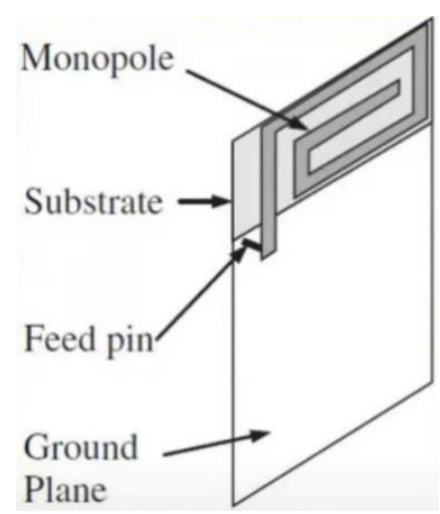

Figure 3: Meandered Line Feeding Monopole

In historical perspective, this complicated design has to concentrate on the types of frequency ranges covered with radiation pattern also we cannot estimate current in the antenna since it is an integrated device.

\section{b. Cell phone Handsets: Currents and radiation patterns}

The placement of the other things like a battery also carries power and we have to look into the arrangements in a design in such a way that we must estimate the power dissipation throughout the antenna circuit, we have to rectify if the current which flows through the conductor carries any additional effects. The overall structure of the mobile also affects the 
radiation pattern. The parasitic effects, nearby circuits, placement of the other devices in a mobile affects the electromagnetic energy distribution were shown in figures [2,3].

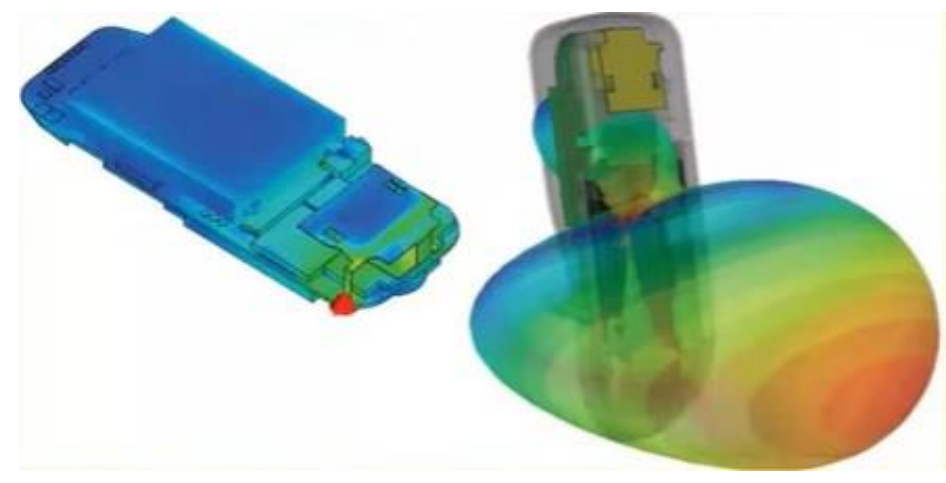

Figure 4: Energy Distribution of Handset Sleeve Dipole

In figure [4] the radiation pattern of the handset sleeve dipole is given. The Capacitive loading, Inductive loading are used in this feeding line meandered technology. The objectives including there are certain frequency ranges that we have to make our cell phones operate and that frequency range have to be covered with designed radiation pattern and proper gain and also constraints are given on this is how antenna design research is focussed in terms of cell phone perspective [1-3].
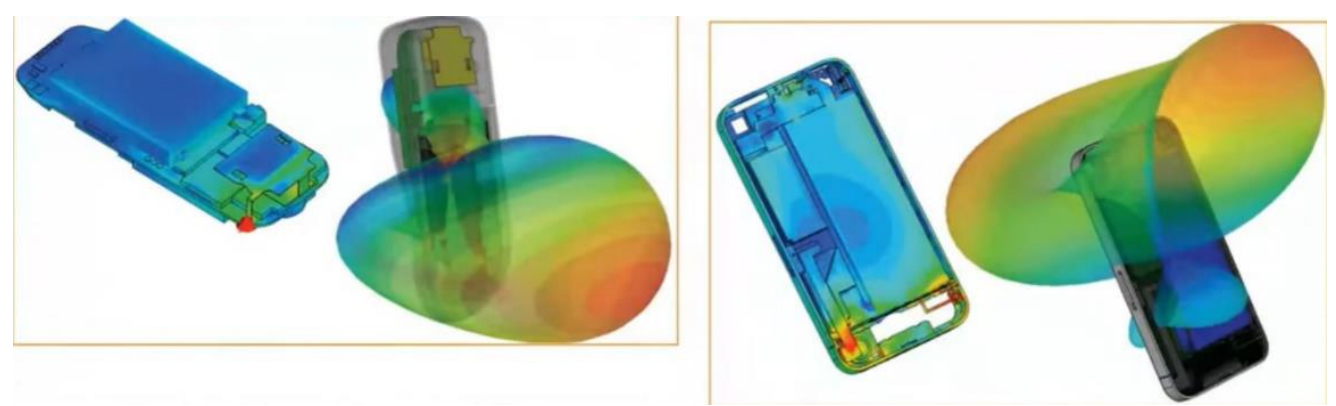

Figure 5: Comparison on Energy Distribution of Handset Sleeve Dipole 1.8GHz Vs iPhone 4 at $1.9 \mathrm{GHz}$

Figure 4 shows the current distribution and 3D radiation pattern of a planar inverted $\mathrm{F}$ antenna (Motorola T193 and planar monopole antenna iPhone 4 but the engineering changes depending on the current situation and challenges [6].

\section{Antennas for Laptops}

In the figure 6 the open slot laptop antenna is used. The laptops are used for various purpose. If we want to connect it to Wi-Fi there has to be antenna in the laptop system.

Important considerations and samples for various laptop applications include

- Location of the antenna in laptop

- Excitation of the antenna in laptop

- Change of boundary conditions

- Size of the device 


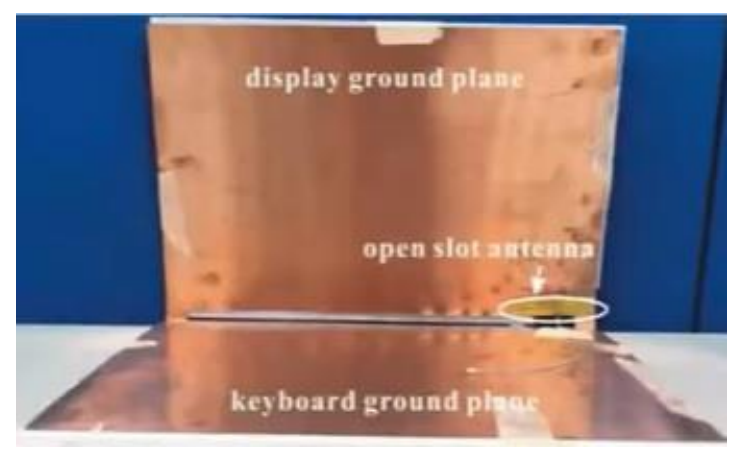

Figure 6: Open Slot Laptop Antenna

\section{Location of antennas in Laptop}

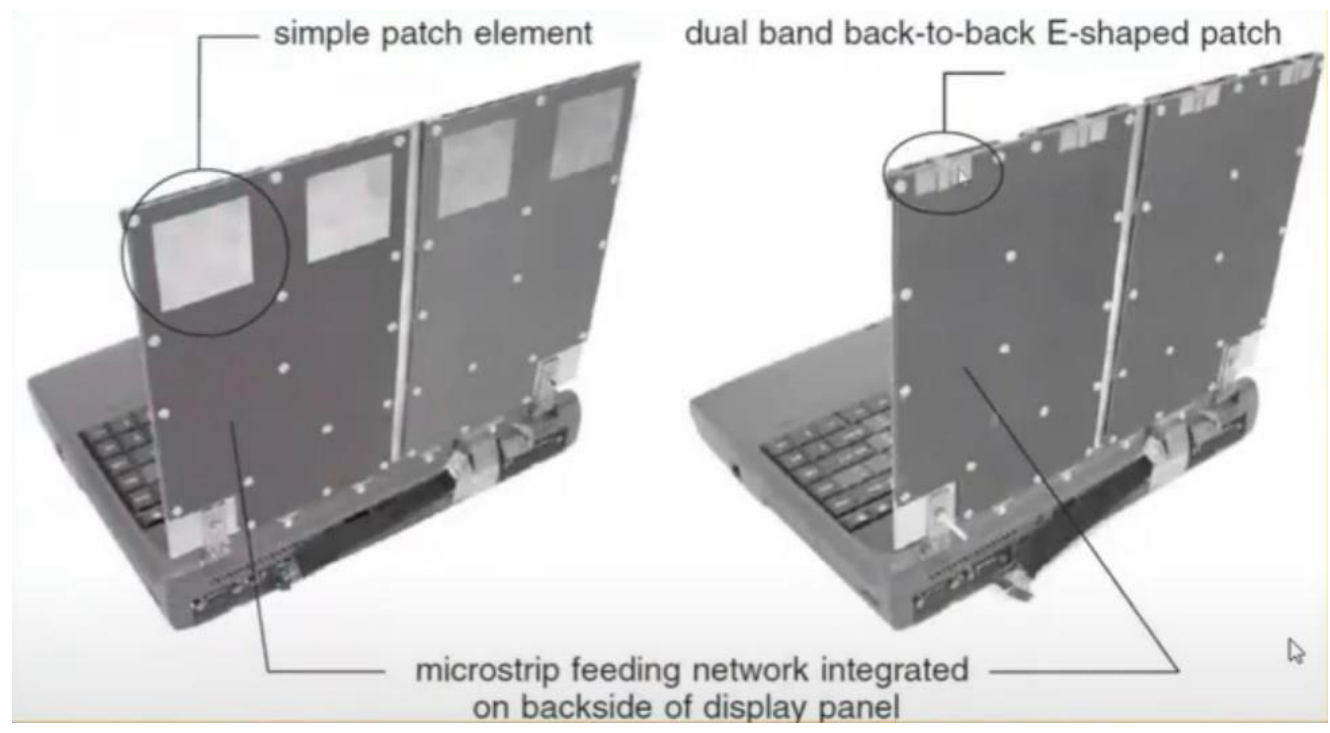

Figure 7: Comparison between simple patch element Vs E - shaped patch

Simple patch element we can see how much area it covers in the above figure and simultaneously in the dual band back-to-back E- shaped patch is also imprinted over the panel of the laptop for MIMO and diversity kind of operations to enhance the data rate [4-5],[7].

\section{Antennas for Satellites and Space}

Low gain and high gain antenna under the rover that serves as transceiver. It is placed on the rover apparatus level. The low-gain type of transceiver actually guides and accepts data in all direction. It also transmits radio waves for deep space network (DSN) antennas and applications on earth. The high gain antenna directs an information in an explicit direction and it is steerable, so the antenna can move to point itself unswervingly to any antenna on ground. 


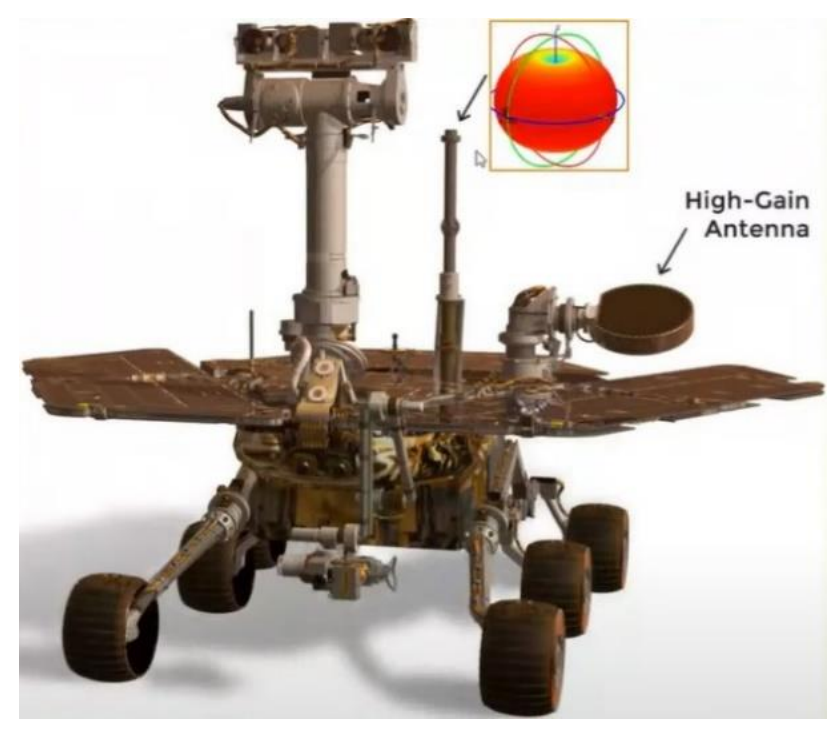

Figure 7: Rover antennas

The benefit of having steerable is that the entire rover doesn't essentially have to modify places to talk to earth [8].

\section{Antennas for television}

We used Ultra High Frequency (UHF) in the frequency range of $300-3000 \mathrm{MHz}$ antennas for Television (TV) applications called Yagi-Uda antenna as shown in figure 8.

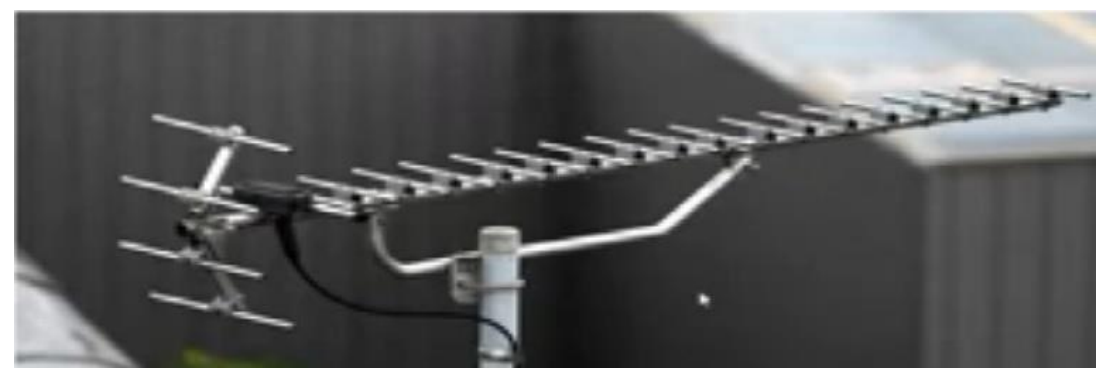

Figure 8: Yagi-Uda Antenna

But now we are looking into this dish antenna and parabolic reflector at the frequency of (9750-10600 MHz) for getting feed and intensive installation in roofs of several housing apartments in the present day [9].

\section{Requirements for the TV transmission}

TV video transmission is drastically different from mobile transmission.

\section{Conclusion}

In this chapter various antenna has been developed which can be used as low-cost product in various fields. The various applications of antenna were introduced in this short communication manuscript. The role of various antennas was explained in all fields with lowcost production. The various applications were given in detail by the design of an antenna. 


\section{Data Availability Statement}

My Manuscript has no associated data

\section{Declaration}

Authors have a responsibility to disclose interests that might appear to affect their ability to present data objectively.

\section{References}

1. Suresh Chinnathampy, M., Aruna, T. \& Muthukumaran, N (2021). Antenna Design: Micro Strip Patch for Spectrum Utilization in Cognitive Radio Networks. Wireless Personal Communications, 119, 959-979.

2. Suresh Chinnathampy, M., Aruna, T. \& Muthukumaran, N. (2021). Design and Fabrication of Micro Strip Patch Antenna for Cognitive Radio Applications. Wireless Personal Communications. https://doi.org/10.1007/s11277-021-08685-9 (Online First Articles)

3. Ramanpreet, N., Rattan, M. \& Gill, S.S (2021). Compact and Low-Profile Planar Antenna with Novel Metastructure for Wearable MBAN Devices. Wireless Personal Communications 118, 3335-3347.

4. Adam, A.A., Rahim, S.K.A., Tan, K.G. et al. (2013). Design of 3.1-12 GHz Printed Elliptical Disc Monopole Antenna with Half Circular Modified Ground Plane for UWB Application. Wireless Personal Communications 69, 535-549.

5. Shashikant, K.R., Kulkarni, A. (2020). Reconfigurable Patch Antenna Design Using Pin Diodes and Raspberry PI for Portable Device Application. Wireless Personal Communications 112, 1809-1828.

6. C. Rowell and E. Y. Lam, (2012). Mobile-Phone Antenna Design. IEEE Antennas and Propagation Magazine, vol. 54, no. 4, pp. 14-34.

7. S. Chen, P. Wu, C. G. Hsu and J. Sze, (2018). Integrated MIMO Slot Antenna on Laptop Computer for Eight-Band LTE/WWAN Operation. IEEE Transactions on Antennas and Propagation, vol. 66, no. 1, pp. 105-114.

8. https://mars.nasa.gov/mer/mission/rover/antennas/

9. A. H. Ballado et al., (2014). Design of indoor microstrip TV antenna for integrated services digital broadcast - Terrestrial (ISDB-T) signal reception at $677 \mathrm{MHz} .2014$ International Conference on Humanoid, Nanotechnology, Information Technology, Communication and Control, Environment and Management (HNICEM), pp. 1-6. 